\title{
EFEKTIVITAS PELATIHAN KETERAMPILAN PENGASUHAN UN- TUK MENURUNKAN STRES PENGASUHAN PADA IBU YANG MEMILIKI ANAK RETARDASI MENTAL
}

\author{
Amilatul Khoiriyyah
}

\section{* Corresponding Author: \\ Universitas Airlangga Surabaya \\ Email: \\ amilatulkhoiriyyah@gmail.com}

\begin{abstract}
Abstrak: Ibu yang terus menerus mengalami stres akan memperparah keadaaan anak yang mengalami retardasi mental. Hal ini akan berakibat buruk dalam pengasuhan karena stres yang dialami seringkali membuat ibu berperilaku tidak sehat dan tidak positif. Tujuan dari penelitian ini adalah untuk mengetahui apakah Pelatihan Keterampilan Pengasuhan dapat menurunkan stres pengasuhan. Metode penelitian ini jenis quasi eksperimen dengan desain single subject. Alat ukur yang digunakan adalah Parenting Stress Index-Short Form untuk mengukur stres pengasuhan. Hasil uji Wilcoxon Signed Rank Test diketahui nilai $\mathrm{z}=2,668$ dengan signifikansi sebesar $0,008<0,05$ maka disimpulkan bahwa ada perbedaan yang sangat signifikan stres pengasuhan sebelum dan sesudah pemberian Pelatihan Keterampilan Pengasuhan. Kata Kunci: Pelatihan Keterampilan Pengasuhan, stres pengasuhan, ibu yang memiliki anak retardasi mental
\end{abstract}

\begin{abstract}
Mothers who are constantly experiencing stress will exacerbate the state of children who have mental retardation. This will have a bad effect in care because the stress experienced often makes mothers behave unhealthy. The purpose of this study is to find out whether Parenting Skills Training can reduce parenting stress. This research method is a quasi-experimental type with a single subject design. The measuring instrument used is the Parenting Stress Index-Short Form to measure parental stress. Wilcoxon Signed Rank Test results known value of $z=2.668$ with a significance of 0.008 $<0.05$, it is concluded that there is a very significant difference in parenting stress before and after the Parenting Skill Training.
\end{abstract}

Keywords: Parenting skills training, parenting stress, mothers with mentally retarded children

\section{PENDAHULUAN}

Transisi sebagai orang tua sangat menekan hampir setiap orang tua dan keluarga. Transisi ini sering melibatkan perubahan dramatis dalam perasaan dan pemikiran, tingkah laku, dan gaya hidup. Hal ini timbul sebagian dari tuntutan untuk merawat anak tetapi juga karena memiliki peran baru dalam keluarga dan masyarakat (Lepore, dalam Deater-Deckard, 2004). Transisi tersebut ditandai dengan meningkatnya distres bagi sebagian orangtua. Hal ini terjadi pada orangtua yang memiliki risiko lebih besar dalam memiliki masalah terhadap peran sebagai orangtua (Taylor \& Kemper, dalam Deater-Deckard, 2004).
Anak merupakan karunia terbesar yang diberikan sang pencipta kepada manusia. Orangtua berharap memiliki anak normal dan sehat, namun pada kenyataannya ada anak yang dilahirkan tidak normal. Anak-anak yang dilahirkan tidak normal dapat juga dikatakan sebagai anak cacat (Azwar, 1999). Salah satu bentuk kecacatan yang sering dijumpai adalah retardasi mental. Data statistik tahun 2004 menunjukkan bahwa sekitar 1-3 persen penduduk Indonesia menderita retardasi mental. Rasio penyandang retardasi mental pada lakilaki dan perempuan di Indonesia adalah 3:2.

Adanya kelahiran seorang anak maka setiap anggota keluarga akan menjalankan peran 
dan fungsi tertentu (Simbolon, 1998). Seorang pria akan menjalani peran sebagai seorang ayah dan berfungsi sebagai pencari nafkah sedangkan seorang wanita akan menjalani peran sebagai ibu yang berfungsi sebagai pengurus rumah tangga serta memelihara, menuntun dan mendidik anak-anak (Kartono, 1992). Menjalani peran sebagai seorang ibu ternyata dapat menyebabkan individu mengalami stres (Noppe \& Noppe, dalam Muslow, dkk, 2002).

Peran wanita sebagai seorang ibu merupakan sumber stres tersendiri dan stres akan semakin besar jika ibu memiliki anak penyandang cacat. Hasil penelitian menunjukkan bahwa ibu yang memiliki anak cacat cenderung mengalami stres yang lebih besar daripada ibu yang memiliki anak normal. Stres pada ibu yang memiliki anak penyandang cacat, khususnya retardasi mental berhubungan dengan permasalahan perilaku anak tersebut. Hal ini diperkuat oleh Walker (1989) bahwa permasalahan perilaku anak penyandang retardasi mental dapat menyebabkan ibu mengalami stres.

Kehadiran anak yang memiliki retardasi mental membawa berbagai perubahan dalam kehidupan orangtua dan membawa mereka pada keadaan baru yang menimbulkan stres karena mengalami perubahan-perubahan penting dan harus memenuhi tuntutan baru, serta menghadapi dan menerima stigma yang tumbuh dalam masyarakat tanpa harus mengisolasi diri (Sarason \& Sarason; Moos \& Schaefer, dalam Sarafino, 1990).

Stres merupakan situasi yang biasa muncul dalam berbagai aspek kehidupan termasuk dalam proses pengasuhan. Pengasuhan terhadap anak yang mengalami hambatan, memunculkan kesulitan tersendiri bagi orangtua karena anakanak yang mengalami retardasi mental memiliki keterbatasan yang signifikan dari fungsi intelektual dan perilaku adaptif, antara lain kemampuan konseptual, sosial, dan keterampilan praktis (AAIDD, 2010).

Floyd dan Gallagher (1997) melakukan penelitian dengan hasil bahwa orang tua dari anak-anak dengan disabilitas intelektual sering mengalami distres yang diakibatkan oleh kekhawatiran dan permintaan terkait dengan anak-anak mereka. Penelitian lain menyebutkan bahwa orang yang terkena dampak tingkat stres yang paling tinggi adalah orangtua yang memiliki anak dengan permasalahan dalam perkembangan kognitif dan sosial (Danseco \& Holden, dalam Deater-Deckard, 2004).

Menurut hasil penelitian yang dilakukan oleh Kumar (2008) orang tua yang memiliki anak dengan intellectual disability/retardasi mental dipastikan lebih mudah mengalami stres psikologis dibandingkan dengan orang tua dari anak normal. Stres diakibatkan karena tuntutan yang harus dipenuhi sebagai orangtua telah melebihi batas sumber daya yang dimiliki oleh orangtua tersebut. Orangtua harus menyeimbangkan antara tuntutan tersebut dengan sumber daya yang mereka miliki.

Menurut Friedrich (Perry, 2004) bahwa salah satu tuntutan penyebab stres pada orang tua dari anak retardasi mental berkaitan dengan ketidakmampuan anak dalam melakukan aktivitas sehari-hari membuat orang tua, khususnya ibu harus selalu membantu dan mendampingi anaknya. Hal itu tentu saja menyebabkan kelelahan fisik. Sedangkan beban psikis yang dirasakan orang tua berkaitan dengan proses penerimaan mulai dari rasa kaget, kecewa, rasa bersalah atas kondisi anak, serta ada tidaknya dukungan dari keluarga. Ditambah lagi dengan beban sosial di mana respon yang negatif dari masyarakat membuat orang tua menjadi malu dan menarik diri dari kehidupan sosial.

Stres yang dialami ibu tidak hanya disebabkan oleh permasalahan perilaku anak saja tetapi juga disebabkan oleh adanya perasaan pesimis ibu akan masa depan anaknya. Little (2000) menyatakan bahwa stres yang dialami oleh ibu dari anak penyandang cacat berhubungan dengan perasaan pesimis ibu akan masa depan anak. Seseorang yang memiliki anak penyandang retardasi mental menganggap bahwa anak cacat memiliki masa depan yang tidak pasti.

Stres pengasuhan juga akan menghambat pekerjaan yang biasa dilakukan sehari-hari bahkan menghambat pertumbuhan individu dalam kehidupannya. Hasil penelitian Yunida (2010) adalah ibu yang memiliki anak retardasi mental mencari dukungan sosial eksternal dari keluarga besar, kelompok orangtua yang memiliki anak retardasi mental, dan tetangga dekat. Penelitian Nachschen, Woodford, dan Minnse (dalam Gunarsa, 2006) menunjukkan rendahnya tingkat adaptasi keluarga cenderung menghambat kemampuan mereka menghadapi tantangan pengasuhan.

Cummins (Small, 2010) menyatakan bahwa pengasuhan pada anak dengan masalah perkembangan merupakan proses yang penuh 
stres bagi orangtua karena seringkali tingkat pengasuhannya lebih sulit dan intensif dibandingkan mengasuh anak dengan perkembangan yang normal. Beberapa penelitian telah menunjukkan bahwa orangtua dari anak dengan intellectual disability akan mengalami tingkat stres pengasuhan yang lebih tinggi dari anak yang tidak memiliki hendaya (Hassall, Rose, \& McDonald, 2005).

Penelitian Gupta dan Singhal (2005) menunjukkan bahwa tingkat stres pada orangtua yang memiliki anak berkebutuhan khusus, lebih tinggi daripada orangtua yang memiliki anak normal. Tingkat stres pada ibu sebesar $70 \%$ dan pada ayah sebesar $40 \%$. Hal ini sesuai dengan Hallahan dan Kauffman (2006) yang mengemukakan bahwa ibu adalah sosok yang lebih rentan terhadap stres dibandingkan ayah.

Penelitian Harris dan McHale (Lam \& Mackenzie, 2002) mengatakan bahwa secara psikologis, ibu kehilangan harapan akan anak yang "normal", menerima kenyataan kehilangan kesempurnaan dari anaknya, mengintegrasikan anak ke dalam keluarga dan merupakan tanggung jawab ibu yang kekal dalam proses pembesaran anak yang berbeda dari orang lain. Ketidakpastian jangka panjang dari kelangsungan hidup anak, kesehatan dan pertumbuhan anak di masa depan adalah faktor penambah stres secara psikologis.

Banyaknya beban yang dirasakan ibu sebagai figur terdekat anak retardasi mental dalam mengasuh anak akan menimbulkan stres pengasuhan. Kondisi stres ibu yang memiliki anak retardasi mental akan menyebabkan ibu mengalami gangguan dalam proses pengasuhan. Hal ini sesuai dengan model stres pengasuhan yang dikemukakan Abidin (Ahern, 2004) bahwa stres mendorong ke arah tidak berfungsinya pengasuhan orangtua terhadap anak, yang timbul karena adanya ketidaksesuaian respon orangtua dalam menanggapi konflik dengan anak-anak mereka.

Besarnya peranan ibu dalam pengasuhan anak retardasi mental yang menyebabkan munculnya stres pada diri ibu, membutuhkan suatu penanganan yang dapat membantu ibu dalam menerapkan pengasuhan yang tepat dan menurunkan tingkat stres. Penanganan tersebut sebagai bentuk dari koping adaptif yang dapat digunakan oleh orangtua dalam mengatasi stres pengasuhan. Strategi koping maladaptif dapat mempengaruhi orangtua maupun anak dalam berperilaku. Sedangkan strategi koping yang adaptif berupa keterampilan problem solving dapat digunakan untuk mengurangi stres pengasuhan pada orangtua (Bushman \& Peacock, 2010). Salah satu keterampilan tersebut yang dapat dilakukan adalah Pelatihan Keterampilan Pengasuhan. Penelitian Ajilchi dan Kargar (2013) kepada 38 ibu-ibu yang mengalami stres menunjukkan bahwa Pelatihan Keterampilan Pengasuhan dapat menurunkan stres pada ibu setelah dilakuan delapan sesi pelatihan.

Penelitian serupa telah dilakuan sebelumnya oleh Rosenberg dan Reppucci (Kissman, 1992) menunjukkan bahwa mengajarkan keterampilan pengasuhan dan strategi penyelesaian konflik untuk ibu-ibu dapat mengurangi stres yang terjadi dalam pengasuhan. Keterampilan pengasuhan wajib untuk diketahui oleh para orangtua, sebagai tuntunan dan membantu para orangtua untuk mendidik anak dan mengasuh anak serta dapat mengatasi permasalahan yang terjadi dalam proses pengasuhan.

Pelatihan Keterampilan Pengasuhan yaitu salah satu teknik yang dapat digunakan untuk memberikan pengetahuan dan keterampilan kepada orangtua tentang bagaimana cara pengasuhan yang tepat dan bagaimana mengatasi stres orangtua. Pelatihan Keterampilan Pengasuhan yang diberikan didasarkan pada keterampilan dasar pengasuhan yang terdiri dari lima aspek sesuai dengan konsep Bailey, Perkins dan Wilkins (1995). Aspek-aspek yang ada di dalam Pelatihan Keterampilan Pengasuhan adalah membangun kepercayaan orangtua terhadap anak (encouragement), kamu bisa (can do), membuat keputusan (choices), mengendalikan diri (self control) dan membangun empati (rescpecting feelings).

Tujuan penelitian ini adalah untuk mengetahui efektivitas Pelatihan Keterampilan Pengasuhan dalam menurunkan stres pengasuhan pada ibu yang memiliki anak retardasi mental.

\section{METODE}

Metode penelitian yang digunakan dalam penelitian ini adalah rancangan quasi experiment, menggunakan single subject design.

Subjek penelitian ini adalah ibu yang memiliki anak dengan diagnosis retardasi mental, berada dalam kategori stres sedang dan berat (berdasarkan pengukuran skala Parenting Stress Index-Short Form), bersedia menjadi partisipan 
dalam penelitian ini, dan belum pernah mengikuti pelatihan serupa. Teknik penetapan sampel dalam penelitian ini menggunakan purposive sampling, yaitu pemilihan sampel sesuai dengan yang dikehendaki oleh peneliti (Marliani, 2013).

Teknik pengumpulan data dalam penelitian ini menggunakan Skala psikologi berupa Parenting Stress Index-Short Form (PSI-SF) yang disusun oleh Richard R. Abidin (Dubbs, 2008). Skala ini terdiri dari 36 aitem pertanyaan yang mengandung tiga aspek stres pengasuhan, di antaranya parent distress (PD), parent-child dysfunction interaction (PCDI), dan difficult child (DC).

Modul dari penelitian ini diadaptasi dari modul yang telah dirancang oleh Bailey, Perkins, dan Wilkins (1995) yang berfokus untuk mengajarkan dasar-dasar keterampilan pengasuhan kepada orangtua. Di antara dasar keterampilan yang diajarkan adalah mengenali kemampuan anak, memahami hal yang boleh dan tidak boleh dilakukan oleh anak, pengambilan keputusan, pengendalian emosi, dan mengapresiasi perasaan anak. Pada pelaksanaannya, pelatihan akan diterapkan dalam 8 sesi yang terdiri dari pra-sesi, sesi inti, dan post-sesi.

Analisis data dilakukan menggunakan wilcoxon signed rank test untuk data non parametrik dengan bantuan aplikasi SPSS 20 for Windows. Analisis data ini untuk menguji hipotesis yang diajukan dalam penelitian. Hipotesis pertama adalah tidak ada perbedaan penurunan stres pengasuhan pada ibu yang memiliki anak retardasi mental antara sebelum dan setelah diberikan Pelatihan Keterampilan Pengasuhan. Hipotesis kedua adalah ada perbedaan penurunan stres pengasuhan pada ibu yang memiliki anak retardasi mental antara sebelum dan setelah diberikan Pelatihan Keterampilan Pengasuhan.

\section{HASIL DAN PEMBAHASAN}

Analisis data yang digunakan untuk melakukan penarikan kesimpulan digunakan untuk menggambarkan ciri dari sebuah populasi berdasarkan data sampel yang tersedia. Hasilnya, kesimpulan pada sampel akan dapat digunakan pada populasi secara keseluruhan. Untuk melakukan analisis tersebut diperlukan metode statistik yang tepat (Santoso, 2015).

Metode statistik yang digunakan dalam penelitian ini adalah metode non parametrik karena jenis data ordinal. Kemudian uji yang akan dilakukan akan menggunakan uji 2 sampel berpasangan wilcoxon sign ranked test yang diguna- kan untuk mengetahui apakah terdapat perbedaan yang signifikan antara sebelum dan setelah pemberian intervensi pada subjek.

Tabel 1. Hasil Analisis Statistik

\begin{tabular}{cc}
\hline Jenis Skor & $\begin{array}{c}\text { Skor Sebelum dan } \\
\text { Setelah Intervensi }\end{array}$ \\
\hline $\mathrm{Z}$ & $-2,668^{*}$ \\
Asymp. sig. 2-tailed &, 008 \\
\hline *berdasarkan skor negatif
\end{tabular}

Hasil analisis uji Wilcoxon Signed Rank Test menunjukkan nilai signifikan sebesar 0,008 < 0,05 yang berarti bahwa terdapat perbedaan Stres Pengasuhan sebelum dan setelah diberikan Pelatihan Keterampilan Pengasuhan sehingga dapat disimpulkan bahwa pemberian Pelatihan Keterampilan Pengasuhan memiliki pengaruh dalam menurunkan stres pengasuhan pada ibu yang memiliki anak retardasi mental.

Uji efektivitas dilakukan untuk mengetahui seberapa besar pengaruh variabel satu terhadap variabel lainnya. Pengujian effect size diperlukan untuk mengetahui apakah intervensi Pelatihan Keterampilan Pengasuhan memiliki pengaruh yang besar terhadap stres pengasuhan dengan melihat nilai skor $\mathrm{Z}$ pada tes Wilcoxon Signed Rank Test.

Diketahui skor Z sebesar 2,668. Setelah dilakukan penghitungan effect size, diperoleh hasil sebesar 1,540 sehingga memenuhi $X \geq 0,8$. Artinya, pengaruh variabel Pelatihan Keterampilan Pengasuhan terhadap variabel stres pengasuhan berada dalam kategori besar.

Pelatihan Keterampilan Pengasuhan mengajarkan keterampilan pengasuhan dan strategi penyelesaian konflik yang dialami oleh ibu-ibu, sehingga dapat mengurangi stres yang terjadi akibat tuntutan peran menjadi orangtua. Keterampilan pengasuhan wajib dimiliki oleh para orangtua sebagai tuntunan dan membantu para orangtua untuk mendidik dan mengasuh anak serta dapat mengatasi permasalahan yang terjadi dalam proses pengasuhan (Rosenberg \& Reppucci, dalam Kissman, 1992).

Pelatihan Keterampilan Pengasuhan yang diberikan kepada ibu-ibu mengajarkan bagaimana orangtua dan anak agar dapat menciptakan interaksi yang baik dalam sebuah keluarga dan membentuk hubungan yang kooperatif antara orangtua dan anak, mengarahkan perilaku anak, memperbaiki hubungan orangtua dan anak serta memberi rasa aman orangtua terhadap anak 
(Bailey, Perkins \& Wilkins, 1995). Setelah subjek menerima Pelatihan Keterampilan Pengasuhan dan mempraktekkannya di rumah, hubungan orangtua dengan anak menjadi lebih baik lagi, hal ini ditunjukkan oleh sikap orangtua dan anak yang saling memberi semangat ketika mereka mengalami permasalahan. Keterampilan pengasuhan yang dipraktekkan ibu-ibu pada anak dapat menciptakan lingkungan yang produktif dalam keluarga dan memberi pengaruh baik bagi perkembangan anak dalam proses pengasuhan.

Komponen Pelatihan Keterampilan Pengasuhan yang dikemukakan oleh Bailey, Perkins, dan Wilkins (1995) merupakan program yang dirancang untuk diterapkan dalam setting kelompok. Ibu diajarkan untuk mampu mengubah perilakunya terlebih dahulu, yang pada akhirnya hal tersebut digunakan untuk mengubah perilaku anak. Komponen dalam Pelatihan tersebut meliputi edukasi dan keterampilan dalam manajemen diri. Keseluruhan isi pelatihan meliputi edukasi tentang karakteristik anak retardasi mental, gaya pengasuhan, serta dasardasar keterampilan pengasuhan yang terdiri dari mengajarkan ibu untuk lebih mengenali kemampuan yang dimiliki anak, mengajarkan anak berperilaku sesuai dengan harapan ibu, mengajarkan cara pengambilan keputusan, cara pengendalian emosi yang dirasakan ibu, dan mengapresiasi perasaan anak.

Pada keterampilan pengasuhan terdapat aspek-aspek yang mempengaruhi diantaranya, aspek membangun kepercayaan orangtua terhadap anak (encouragement) yang memberikan keterampilan sosialisasi yang menjadi dasar dalam menghargai diri sendiri dan orang lain. Encouragement memberikan para orangtua sebuah cara untuk mengekspresikan perasaan-perasaan positif mereka terhadap anak-anak. Perubahan yang ditunjukkan anak membuat frustasi-frustasi yang dialami orangtua menurun. Apabila hal tersebut secara konsisten dilakukan anak secara terus-menerus maka dapat membantu orangtua untuk menurunkan stres yang dialami dalam pengasuhan (Gordon, dalam Bailey, Perkins \& Wilkins, 1995).

Kamu bisa (can do) mengajarkan kepada para orangtua bagaimana mengarahkan perilaku-perilaku anak agar menjadi baik dengan cara menyampaikan pesan-pesan positif dan bersahabat. Setelah diberikan keterampilan ini, ibu-ibu menanamkan sikap positif dalam diri anak. Perubahan perilaku anak yang tidak dapat diterima dapat diubah dengan lingkungan yang positif. Hal ini dapat menjadi cara sederhana dan efektif untuk mengurangi frustasi yang dialami anak. Rendahnya frustasi-frustasi yang dialami anak juga dapat menurunkan stres pengasuhan yang dialami oleh orangtua (Gordon, dalam Bailey, Perkins \& Wilkins, 1995).

Membuat keputusan (choices) memberikan pengetahuan tentang bagaimana bernegosiasi yang menghormati hak-hak baik orangtua maupun anak-anak. Choices mengajarkan kerjasama antara orangtua dengan anak. Orangtua dapat membantu anak. dalam mengambil keputusan terhadap situasi yang sedang dihadapi anak. Setelah diberikan keterampilan pengasuhan pada ibu-ibu dan ibu-ibu mempraktekkan choices pada anak maka terlihat ada perubahan pada perilaku anak. Bila perilaku tersebut terus-menerus ditunjukkan anak maka kecemasan-kecemasan orangtua terhadap berbagai situasi yang berkaitan dengan anak akan berkurang dan kemandirian anak terhadap dirinya semakin meningkat. Kemandirian yang lebih positif dapat membantu orangtua dalam mengatasi stres pengasuhan (Bailey, Perkins \& Wilkins, 1995).

Mengendalikan diri (Self control) merupakan keterampilan yang membantu para orangtua untuk tidak berperilaku yang dapat menyakiti anak. Kontrol diri sangat dibutuhkan orangtua sebelum dapat memutuskan bagaimana bertindak kepada anak sehingga orangtua dapat berinteraksi dengan anak-anak dengan cara-cara yang baik, bahkan dalam kondisi yang penuh tekanan. Setelah mempraktekkan keterampilan ini, ketika ibu-ibu sedang marah kepada anak maka ibu mengendalikan dirinya dengan bermacam cara, misalnya dengan menghindar dari anak beberapa waktu sampai kemarahan ibu sudah reda, mengatur pernafasan, berdiam diri sejenak, dan yang lainnya. Ibu harus dapat mengatasi hal-hal yang dapat memicu kemarahan dengan belajar mengendalikan diri, mengurangi perilaku-perilaku aversif dan meningkatkan perilaku prososial. Sehingga stres pengasuhan tidak terjadi dan orangtua dapat mengendalikan emosi menjadi lebih baik (Goldstein, dalam Bailey, Perkins \& Wilkins, 1995).

Membangun empati (respecting feelings) merupakan keterampilan yang membantu para orangtua agar mengerti perasaan-perasaan anak, mengerti apa yang anak butuhkan sehing- 
ga orangtua dapat memenuhi apa yang dibutuhkan anak. Dengan demikian interaksi yang baik dapat terjalin diantara orangtua dan anak. Hasil penelitian yang ditunjukkan ibu-ibu adalah ada perubahan sikap dan perilaku anak ketika ibu-ibu menunjukkan perasaan sayang melalui perilaku menemani anak hingga tertidur, tidak memarahi anak ketika menunjukkan perilaku yang tidak sesuai dengan harapan ibu, dan lainnya. Orangtua yang selalu mengungkapkan perasaan terhadap anak akan membantu anak memahami emosi-emosi yang ada dalam diri anak. Bila anak diberi kesempatan untuk mengatakan emosi yang ada dalam dirinya maka anak akan belajar memahami dirinya. Bila hal ini terus-menerus ada dalam diri anak maka anak akan dapat membuat penyelesaian terhadap stres yang dialaminya (Dinkmeyer \& McKay, dalam Bailey, Perkins \& Wilkins, 1995).

Johnson dan Johnson (2001) mengemukakan bahwa ada beberapa faktor yang mempengaruhi suatu pelatihan, yaitu partisipan, iklim pelatihan, gaya belajar partisipan, strategi pelatihan, topik pelatihan, teknik pelatihan, fasilitas pendukung dan keterbatasan. Dalam hal ini keberhasilan Pelatihan Keterampilan Pengasuhan dalam menurunkan stres pengasuhan pada ibu yang memiliki anak Retardasi Mental turut dipengaruhi oleh beberapa faktor penting yaitu modul pelatihan, trainer, dan kerjasama partisipan.

Modul pelatihan ini disusun oleh peneliti melalui teori yang relevan, serta sudah dilakukan profesional judgment. Metode pelatihan yang terinci secara jelas dan runtut serta merupakan adaptasi dari metode Parenting Skill yang pertama kali dikemukakan oleh Bailey, Perkins, dan Wilkins (1995) yang digabungkan dengan pendekatan kelompok, serta disesuaikan dengan keadaan partisipan, sehingga membuat modul semakin lengkap.

Metode yang dilakukan dalam pelatihan ini adalah presentasi, sharing, pemutaran video, penyajian kasus dan diskusi kelompok. Metode tersebut dipilih untuk mendukung pendekatan experiential learning. Pada pendekatan experiential learning, peserta mendapatkan pemahaman dari pengalaman atau aktivitas yang dilakukan (Prawitasari, 1998). Leigh (2006) menjelaskan bahwa kesempatan untuk berdiskusi dan berbagi pengalaman merupakan salah satu manfaat yang bisa didapatkan jika mengikuti pelatihan. Hasil observasi selama kegiatan pelatihan ber- langsung menunjukkan bahwa sebagain besar peserta pelatihan terlibat aktif dalam kegiatan yang dilaksanakan selama pelatihan.

Pada sesi-sesi pelatihan, peserta diajak untuk sharing mengenai pengalaman masing-masing ibu dalam mengasuh anaknya. Pada kesempatan kali ini, menunjukkan universalitas pada peserta. Kelompok merasa memiliki satu pemikiran, permasalahan dan ide tentang anak retardasi mental. Mereka juga dapat bertukar pengalaman dan informasi, sehingga mampu menambah wawasan serta keterampilan yang baru. Hal tersebut sesuai dengan pendapat Yalom (2005) bahwa pendekatan kelompok mampu menjadi salah satu terapi. Pada sesi materi retardasi mental, peserta dapat mengidentifikasi hal-hal yang berkaitan dengan anak retardasi mental.

Menurut Johnson dan Johnson (2001), pemberi materi menjadi bagian yang sangat penting dalam menentukan kesuksesan dan efektivitas pelatihan. Peserta menilai fasilitator memuaskan dalam penguasaan dan penyampaian materi, bersikap dan bertingkah laku, serta dalam penggunaan bahasa. Fasilitator memberi penguatan, merefleksikan pengalaman, memotivasi, serta berbagi pengalamannya bersama partisipan. Homogenitas tingkat pendidikan peserta mempermudah fasilitator dalam menyampaikan materi.

Partisipasi peserta juga mendukung keberhasilan pelatihan. Keterlibatan aktif dan pengalaman belajar dapat menjadi modal terjadinya transfer belajar yang optimal bukan hanya sebagai penerima informasi pasif (Goldstein, 1981). Selama pelatihan, peserta cukup aktif berpendapat, menjawab pertanyaan, maupun berbagi pengalaman. Antusiasme peserta juga ditunjukkan dengan kehadiran seluruh peserta secara penuh selama 3 kali pertemuan yang terdiri dari 8 sesi.

Menurut Goldstein (1981), tujuan utama suatu pelatihan adalah peserta mampu mentransfer materi yang diperoleh dalam pelatihan ke dalam kehidupan sehari-harinya. Pelatihan ini juga menggunakan pendekatan kelompok yang ikut mendukung keberhasilan dalam penelitian ini. Pelatihan dalam setting kelompok lebih menguntungkan jika masing-masing anggota kelompok memiliki permasalahan yang relatif sama. Adanya kesamaan permasalahan dapat menciptakan universalitas, yaitu peserta menyadari bahwa ada individu lain yang men- 
galami masalah serupa dengan dirinya (Yalom, 2005). Seluruh peserta pelatihan adalah ibu yang memiliki anak retardasi mental. Adanya kesamaan menciptakan keterbukaan di antara peserta. Kesamaan tersebut juga mempermudah peserta untuk berbagi informasi, bertukar pengalaman, serta saling memberi dukungan.

Menurut Rose (2002), keuntungan pelaksanaan dalam kelompok dibanding dengan individual adalah anggota kelompok akan saling mendukung, memberikan keyakinan, dan dapat berbagi dengan anggota lain sehingga terjadi hubungan yang menyembuhkan antar anggota kelompok. Kelompok akan memberikan rasa aman bagi individu sehingga mereka bisa berkomunikasi dan akan menerima dukungan dari terapis dan anggota lainnya serta memberikan kesempatan bagi orang lain untuk diamati (Valizadeh dkk, 2009). Subjek saling bertukar pengalaman tentang cara mengasuh anak, memberikan alternatif solusi ketika muncul permasalahan dengan anak atau keluarga lain, dan saling menguatkan ketika terdapat subjek yang mendapatkan pandangan negatif dari orang lain terkait kondisi anak.

Johnson dan Johnson (2001) juga mengungkapkan hal yang serupa bahwa pendekatan kelompok lebih menguntungkan daripada pendekatan individual karena pendekatan kelompok memungkinkan terjadinya proses katarsis bersama, saling memberi dukungan, adanya perasaan berbagi, sehingga suasana akan terasa nyaman, aman, kekeluargaan dan penuh empati, dan diharapkan dapat berpengaruh terhadap peningkatan toleransi terhadap keadaan stres. Kelompok yang telah terbentuk pada saat pelatihan, tetap berjalan hingga pelatihan selesai sehingga anggota kelompok dapat tetap saling memberikan dukungan meskipun di luar pelatihan.

\section{KESIMPULAN DAN SARAN \\ Kesimpulan}

Berdasarkan analisis data dan pembahasan, dapat disimpulkan bahwa Pelatihan Keterampilan Pengasuhan terbukti dapat menurunkan stres pengasuhan pada subjek penelitian yang memiliki anak retardasi mental. Pelatihan Keterampilan Pengasuhan dapat menurunkan stres pengasuhan yang dipengaruhi oleh penerapan encouragement, can do, choices, self control dan respecting feeling. Encouragement mengajarkan cara mengekspresikan perasaan positif, can do mengajarkan penanaman sifat positif pada anak, choices mengajarkan pengambilan keputusan, self control mengajarkan keterampilan pengendalian diri, dan respecting feeling mengajarkan tentang pentingnya memahami emosi anak.

Berdasarkan penelitian yang telah dilakukan, peneliti memiliki saran untuk pihak terkait. Saran untuk subjek penelitian adalah menghimbau agar konsisten menerapkan keterampilan-keterampilan yang telah dipelajari selama intervensi berlangsung dan aktif dalam support group yang telah dibentuk pada saat intervensi.

\section{Saran}

Saran untuk peneliti selanjutnya adalah dapat mempertimbangkan untuk menambah jumlah sampel agar hasil dapat digeneralisasikan. Jika bertempat di sekolah, maka perlu adanya koordinasi dengan pihak sekolah bahwa tempat intervensi membutuhkan kondisi yang kondusif.

\section{REFERENSI}

Ahern, L. S. (2004). Psychometric properties of the parenting stress index-short form [Unpublished master's thesis]. [North Calorina]: North Carolina State University.

Ajilchi, B., dan Kargar, F. R. (2013). The impact of parenting skills training program on stressed mothers and their children's depression level. Social and Behavioral Science. 84:450-456.

American Association on Intellectual and Developmental Disabilities. (2010). Frequently Asked Questions on The AAIDD 11 th Edition of Intellectual Disability: Definiton, Classification, and Systems of Supports. Washington: The AAIDD Terminology and Classification Committee.

Azwar, S. (1999). Pengantar psikologi inteligensi (Cetakan II). Yogyakarta: Pustaka Pelajar.

Bailey, J., Perkins, S., dan Wilkins, S. (1995). Parenting skills workshop series. A manual for parent educators. New York: Cornel University. Bushman, B. B., dan Peacock, G. G. (2010). Does teaching problem-solving skills matter? An evaluation of problem-solving skills training for the treatment of social and behavioral problems in children. Child $\mathcal{E}$ Family Behavior Therapy. 32(2), 103-124.

Deater-Deckardd, K. (2004). Parenting stress. United States of America: Nick Hornby.

Dubbs, J. L. (2008). Parent stress reduction 
through a psychosocial intervention for children diagnosed with attention-deficit/ hyperactivity [Unpublished doctoral dissertation]. [United States] Indiana University of Pennsylvania.

Floyd, F. J., dan Gallagher, E. M. (1997). Parental stress, care demands and use of support services for school age children with disabilities and behavior problems. Family Relations. 46:359-371.

Goldstein, A. P. (1981). Psychological skill training: The structured learning technique. New york: Pergamon Press.

Gunarsa, D. S. (2006). Dari anak sampai usia lanjut: Bunga rampai psikologi perkembangan. Jakarta: PT. BPK Gunung Mulia.

Gupta, A., dan Singhal, N. (2005). Psychosocial support for families of children with autism. Asia Pasific Disability Rehabilitation Journal. 16(2): 62-83.

Hallahan, D. P., dan Kauffman, J. M. (2006). Exceptional children: An introduction to special education (10th ed.). Boston: Pearson.

Hassall, R., Rose, J., dan McDonald, J. (2005). Parenting stress in mothers of children with an intellectual disability: The effects of parental cognitions in relation to child characteristics and family support. Journal of intellectul disability research. 49(6), 405-418.

Johnson, C. A., dan Johnson, F. P. (2001). Joining together: Group theory and group skills. Boston: Allyn \& Bacon.

Kartono, K. (1992). Psikologi wanita: Mengenal wanita sebagai ibu dan nenek (Jilid 2). Bandung: Mandar Maju.

Kissman, K. (1992). Parent skills training: Expanding scholl-based services for adolescent mothers. Research on Social Work Practic, 2(2): 161-171.

Kumar, G. V. (2008). Psychological stress and coping strategies of parents of mentally challenged children. Journal of the Indian Academy of Applied Psychology. 34(2): 227231.

Lam, L. W., dan Mackenzie, A. E. (2002). Coping with a child with down syndrome: The experiences of mothers in Hong Kong. Qualitative Health Research. 12(2): 223-237.

Leigh, D. (2006). The group trainer's handbook: Design and delivery training for group. London: Kogan Page.

Little, L.(2002). Difference in stress and coping for mothers and fathers of children with as- perger's syndrom and nonverbal learning disorders, Journal od Pediatric Nursing. 28, 565.

Marliani, R. (2013). Psikologi eksperimen. Bandung: Pustaka Setia.

Muslow, Miriam, dkk. (2002). Multilevel factors influencing maternal stress during the first three years. Journal of Marriage and Family. Minneapolis. 64,944.

Perry, A. (2004). A model of stress in families of children with developmental disabilities: Clinical and research application. Journal on Developmental Disabilities. 11(1).

Prawitasari, J. E. (1998). Pengalihan metode action research ke petugas puskesmas untuk meningkatkan perilaku sehat masyarakat. Anima. 8(52): 323-333.

Rose, S. D. (2002). Encyclopedia of psychotherapy. New York: Elsevier.

Santoso, S. (2015). Menguasai Statistik Non Parametrik. Jakarta: PT Elex Media Komputindo.

Sarafino, E. P. (1990). Health psychology. Canada: John Willey \& Sons, Inc.

Simbolon, M. J. (1998). Stress pada anak dan remaja. Akademia. Medan: Universitas Islam Sumatera Utara.

Small, R. P. (2010). A comparison of parental self-efficacy, parenting satisfaction, and other factors between single mothers with and without children with developmental disabilities [Unpublished doctoral dissertation]. [Michigan] Wayne State University.

Valizadeh, S. (2009). The effectiveness of group coping skills training on reducing stres of mothers with disabled children. Iranian Rehabilitation Journal. 7(10).

Yalom, I. D. (2005). The theory and practice of group psychotherapy. New York: Basic Books.

Yunida, T. (2010). Stres dan koping keluarga dengan anak tuangrahita di SLB dan SLB-C1 widya bakti Semarang. [Skripsi tidak dipublikasikan]. [Semarang] Universitas Diponegoro. 